\title{
Controle hormonal do déficit hídrico em tomateiro
}

\author{
Hormonal control of drought in tomato
}

Paula Cristina da Silva Souza (ORCID 0000-0001-5636-8275), Fernando Boschi Martins (ORCID 0000-0001-8120-4862),
Lucas Aparecido Gaion* (ORCID 0000-0003-4246-1975)

Universidade de Marília, Marília, SP, Brasil. *Autor para correspondência: lucas.gaion@yahoo.com.br

Submissão: 12/05/2021 | Aceite: 12/09/2021

\begin{abstract}
RESUMO
O déficit hídrico é um dos principais fatores limitantes da produção agrícola. Por isso, as plantas têm desenvolvido mecanismos de sobrevivência e aclimatação à condição de déficit hídrico, por exemplo, o fechamento estomático que visa minimizar a perda de água pela planta. Com efeito, as respostas das plantas ao déficit hídrico são controladas diretamente pelo balanço hormonal. Assim, o objetivo do presente estudo foi avaliar como diferentes mutantes hormonais de tomateiro respondem à condição de déficit hídrico. Foram utilizados cinco genótipos de tomateiro, o cultivar Micro-Tom (MT), tipo selvagem, os mutantes Never ripe ( $\mathrm{Nr}$ ), com baixa sensibilidade ao etileno, diageotropica (dgt), com baixa sensibilidade à auxina, e os transgênicos L19 (com elevada biossíntese de giberelina) e SL (com baixa biossíntese de estrigolactonas). As plantas foram cultivadas em vasos de polietileno com capacidade para $350 \mathrm{~mL}$ preenchidos com substrato comercial. Durante o desenvolvimento, todas as plantas foram diariamente irrigadas até o início do déficit hídrico, 37 dias após a semeadura (DAS). A fim de induzir o déficit hídrico, a irrigação foi suspensa em parte das plantas por um período de sete dias. Plantas-controle foram irrigadas continuamente. Depois de sete dias nas respectivas condições (irrigada e déficit hídrico), as plantas foram colhidas para a realização das análises de crescimento, conteúdo relativo de água (CRA) e extravasamento de eletrólitos. Como esperado, plantas de L19 exibiram maior altura de plantas, enquanto plantas de SL apresentaram maior acúmulo de massa fresca e seca da parte aérea em condição controle. Em condição de déficit hídrico, observou-se redução de massa fresca e altura de plantas em todos os genótipos avaliados. Enquanto que apenas plantas de MT e SL não sofreram redução de massa seca da parte aérea em função da restrição hídrica. Quanto ao CRA, apenas plantas de L19 não apresentaram redução sob condição de déficit hídrico.
\end{abstract}

PALAVRAS-CHAVE: auxina, giberelina, Micro-Tom.

\section{ABSTRACT}

Drought stress is one of the main limiting factors of crop production. For this reason, plants have developed mechanisms of survival and acclimatization to the drought condition, for instance, the stomatal closure to minimize the loss of water by the plant. In effect, the plant's responses to water deficit are directly controlled by the hormonal balance. Thus, the present study aimed to evaluate how different tomato hormonal mutants respond to drought stress. Five tomato genotypes were used, the cultivar MicroTom (MT), wild-type, the mutants Never ripe (Nr), with low sensitivity to ethylene, diageotropica (dgt), with low sensitivity to auxin, and the transgenic L19 (with high biosynthesis of gibberellin) and SL (with low biosynthesis of strigolactones). Plants were grown in polyethylene pots with $350 \mathrm{~mL}$ filled with commercial substrate. During development, all plants were irrigated daily until the beginning of the drought stress, 37 days after sowing (DAS). Then, irrigation was suspended in part of the plants for seven days to induce drought. Control plants were irrigated continuously. After seven days in the respective conditions (irrigated and drought stress), the plants were harvested to analyze the growth, relative water content (RWC), and electrolyte leakage. As expected, L19 plants exhibited higher height, while SL plants showed greater fresh and dry shoot weight accumulation in control conditions. In drought stress conditions, a reduction in fresh weight and plant height was observed in all evaluated genotypes. In contrast, only MT and SL plants did not suffer a reduction in dry mass of the aerial part due to water restriction. As for the CRA, only L19 plants did not show a reduction under water deficit conditions.

KEYWORDS: auxin, gibberellin, Micro-Tom. 


\section{INTRODUÇÃO}

Ao longo de seu ciclo de vida, as plantas são submetidas a diversas condições ambientais extremas (HARTMAN \& TRINGE 2019, HASANUZZAMAN et al. 2020, HUNTER et al. 2021). Dentre estas condições, o déficit hídrico é o principal fator limitante à produção agrícola ao redor do mundo (PARRY et al. 2005, MODANESI et al. 2020). Dessa forma, como mecanismo de sobrevivência, as plantas necessitam responder eficientemente a restrição da disponibilidade hídrica. Assim, a partir da percepção, vias de sinalização do déficit hídrico são induzidas, levando a modificações moleculares, bioquímicas, fisiológicas e, finalmente, morfológicas (SARWAT \& TUTEJA 2017, LIANG et al. 2020).

Essas alterações são causadas por mudanças relacionadas a mecanismos de aclimatação das plantas ao déficit hídrico, como regulação da abertura e fechamento dos estômatos (SARWAT \& TUTEJA 2017, HASAN et al. 2021), redução da produção fotossintética, modificação da partição de carbono entre a parte aérea e a raiz (KAGE et al. 2004, KAPOOR et al. 2020). Todas essas modificações são intimamente controladas pelo balanço hormonal da planta sob condição de estresse (FEITOSA et al. 2016). De fato, diversos trabalhos têm relatado o envolvimento de diversos hormônios, como etileno, auxina, giberelina e estrigolactona, com a modulação dos mecanismos de sinalização e aclimatação ao déficit hídrico (SELLIN et al. 2014, CUl et al. 2015, DE OLLAS \& DODD 2016).

Por exemplo, as estrigolactonas (SL), hormônio que atua na regulação da ramificação lateral, demonstraram resultados positivos sob condição de estresse hídrico (VISENTIN et al. 2016). Os autores observaram que plantas de tomateiro com baixa biossíntese de SL perderam, pelo menos parcialmente, a capacidade de sinalização do déficit hídrico e, consequentemente, tornaram-se extremante sensíveis a seca (VISENTIN et al. 2016). Por outro lado, tem sido relatado que genes envolvidos com a biossíntese e transporte de SL são inibidos em condições de seca, dificultando assim o transporte de SL a partir das raízes de tomateiro para a parte aérea, visto que as raízes são o local de maior produção do hormônio (LIU et al. 2016, RUIZ-LOZANO et al. 2016, FAHAD et al. 2017). Esses resultados indicam que as SL são as moléculas diretamente transportadas a partir do sistema radicular para sinalização do déficit hídrico, mas que atua modulando a sua sinalização.

Por sua vez, as auxinas (AUX) têm sido relacionadas à atenuação dos efeitos da seca, atuando em nível celular, regulando o metabolismo vegetal e estimulando o crescimento das raízes (SHI et al. 2014, SERGIEV et al. 2019). Neste caso, o maior desenvolvimento radicular favorece a maior captação de água pela planta. Similarmente, o etileno $(E T)$, um hormônio gasoso, vem sendo associado constantemente às respostas ao déficit hídrico (ZHU et al. 2018). Por exemplo, GRAVES e GLADON (1985) associaram o déficit hídrico à intensa produção de etileno, que poderia ser retardada em plântulas de ervilha com ABA endógeno, em concentrações de 0,1 $\mu \mathrm{M}$ a $1 \mu \mathrm{M}$ (GERTMAN \& FUCHS 1972).

Por fim, as giberelinas (GA), hormônios essenciais para o crescimento da parte aérea e germinação de sementes, demonstram relações diretas com os efeitos causados pela seca (PIMENTA LANGE \& LANGE 2006, GAION et al. 2018). De fato, observa-se que mutantes de trigo com reduzida biossíntese de GAs apresentaram maior tolerância a condição de seca (LANDJEVA et al. 2008, ALGHABARI et al. 2014). No entanto, outros estudos têm relacionado os danos causados pela seca em plantas milho com a redução de GAs (WANG et al. 2008, COELHO FILHO et al. 2013, LIU et al. 2013).

Nesse contexto, objetivou-se estudar como a diferente biossíntese ou percepção dos hormônios AUX, GA, ET e SL modulam as respostas do tomateiro à condição de déficit hídrico. Aqui, nós hipotetizamos que a modificação do metabolismo hormonal nos mutantes de tomateiro tornará esses genótipos mais ou menos sensíveis ao déficit hídrico dependendo da classe hormonal alterada.

\section{MATERIAL E MÉTODOS}

No presente experimento, foram utilizados cinco genótipos de tomateiro, o cultivar Micro-Tom (MT), os mutantes Never ripe (Nr), diageotropica (dgt), e os transgênicos L19 e SL (Tabela 1) (BASSEL et al. 2008, CARRERA et al. 2012). Sementes dos genótipos foram colocadas para germinar em bandejas de poliestireno contendo mistura na proporção de 1:1 de substrato comercial (Carolina Soil ${ }^{\circledR}$ ) e fibra de casca de coco, suplementado com $1 \mathrm{~g} \mathrm{~L}^{-1}$ de NPK 10:10:10 e $4 \mathrm{~g} \mathrm{~L}^{-1}$ de calcário dolomítico. Aos 15 dias após a semeadura (DAS), as plantas foram transferidas para vasos de $350 \mathrm{~mL}$ e transferidas para a casa de vegetação.

Todas as plantas foram diariamente irrigadas até o início do déficit hídrico, aos 37 DAS. A fim de induzir o déficit hídrico, a irrigação foi suspendida em parte das plantas por um período de sete dias. Plantas-controle foram irrigadas continuamente. Depois de sete dias nas respectivas condições (irrigada e déficit hídrico), as plantas (45 DAS) foram coletadas para a realização das análises como descrito abaixo. 
Tabela 1. Caracterização dos genótipos de tomateiro utilizados no experimento.

Table 1. Characterization of tomato genotypes used in the experiment.

\begin{tabular}{lll}
\hline Genótipo & Caracterização & Referência \\
\hline Micro-Tom (MT) & $\begin{array}{l}\text { Presença do gene Dwarf, que confere o porte anão às } \\
\text { plantas }\end{array}$ & $\begin{array}{l}\text { CARVALHO et al. } \\
\text { (2011) }\end{array}$ \\
& Baixa sensibilidade ao etileno devido à perda de função & HAMILTON et al. \\
do gene LeETR3 que codifica um receptor do etileno $(\mathrm{Nr})$ & $(1990)$ \\
Diageotropica $($ dgt) & $\begin{array}{l}\text { Baixa sensibilidade à auxina devido à perda de } \\
\text { capacidade de biossíntese da proteína ciclofilina }\end{array}$ & $\begin{array}{l}\text { KELLY \& BRADFORD } \\
\text { (1986) }\end{array}$ \\
& $\begin{array}{l}\text { Planta transgênica com elevada biossíntese de giberelina } \\
\text { L19 }\end{array}$ & GARCÍA-HURTADO et \\
em função da superexpressão do gene GA20ox & al. (2012) \\
& Planta transgênica com baixa biossíntese de & VISENTIN et al. (2016) \\
& estrigolactonas em função do silenciamento do gene & \\
& SLCCD7 & \\
\hline
\end{tabular}

A altura das plantas foi determinada usando uma régua graduada. A massa fresca (MF) tanto da parte aérea como das raízes foi determinada em balança analítica (Denver Instrument Company AA-200) com precisão de $0,0001 \mathrm{~g}$. Em seguida, o material foi mantido em saco de papel e levado à estufa com circulação forçada de ar a $60{ }^{\circ} \mathrm{C}$ por 72 horas e, em seguida, determinada a massa seca (MS) da parte aérea e das raízes utilizando-se balança analítica (Denver Instrument Company AA-200) com precisão de $0,0001 \mathrm{~g}$.

O conteúdo relativo de água (CRA) foi obtido usando discos foliares, aproximadamente $200 \mathrm{mg}$ de MF. Para tanto, após a coleta e pesagem, os discos foliares foram acondicionados em placas de petri acrescidas de água deionizada, e mantidas na ausência de luminosidade por cinco horas. Após esse período, foi retirado o excesso de água superficial dos discos utilizando-se papel toalha e foram pesados para a obtenção da massa túrgida (MT). Sequencialmente, a massa seca (MS) dos discos foi obtida através da secagem em estufa de circulação forçada a $60{ }^{\circ} \mathrm{C}$, por um período de $48 \mathrm{~h}$. Assim, o CRA foi determinado pela seguinte fórmula: (MF-MS)/(MTMS) x 100 (TURNER 1981).

O extravasamento de eletrólitos será verificado obtendo-se cinco discos foliares de cada planta, inicialmente, os mesmos serão deixados em repouso em placas de Petri contendo $20 \mathrm{~mL}$ de água deionizada, por $90 \mathrm{~min}$, a $25{ }^{\circ} \mathrm{C}$ sendo, em seguida, medida a condutividade inicial (Xi) das amostras. Posteriormente, as mesmas foram submetidas a $80{ }^{\circ} \mathrm{C}$, por $90 \mathrm{~min}$, em estufa de secagem e, após resfriamento, medida a condutividade final (Xf). A porcentagem de extravasamento de eletrólitos foi expressa pela fórmula: [(Xi/Xf) x 100] (KOVALESKI \& GROSSMAN 2021).

Empregou-se o delineamento inteiramente casualizado em esquema fatorial $5 \times 2$; constituído por cinco genótipos (MT, Nr, dgt, L19 e SL) e duas condições (irrigada e déficit hídrico), e quatro repetições. Todos os dados foram submetidos à análise de variância (ANOVA), e as médias foram comparadas pelo teste de Scott-Knot ( $\mathrm{p} \leq 0.05)$, utilizando o programa AgroEstat (www.agroestat.com).

\section{RESULTADOS E DISCUSSÃO}

\section{Controle hormonal do crescimento do tomateiro sob condição irrigada}

Sob condição irrigada, como esperado, observou-se que plantas de L19, com elevada biossíntese de GA, exibiram maior altura (Figura $1 \mathrm{~A}$ ). Por outro lado, plantas de dgt, baixa sensibilidade às auxinas, apresentaram menor altura das plantas, seguidas em ordem crescente por plantas de $\mathrm{Nr}$, MT e SL (Figura 1A). Com relação à massa fresca da parte aérea, plantas com biossíntese reduzida de SLs apresentaram maior massa fresca da parte aérea em comparação aos demais genótipos (Figura 1B). Enquanto que plantas de dgt exibiram menor massa fresca da parte aérea (Figura 1B). Semelhante à massa fresca da parte aérea, plantas de SL apresentaram maior massa fresca do sistema radicular em relação aos demais genótipos, que não diferiram entre si (Figura 1B).

Quanto ao acúmulo de massa seca da parte aérea, notou-se que plantas de MT, $\mathrm{Nr}$ e SL exibiram maior acúmulo de massa seca na parte aérea quando comparadas às plantas de dgt e L 19 , sob condição irrigada (Figura 1C). Avaliando o sistema radicular observou-se maior acúmulo de massa seca em plantas de SL, enquanto os demais genótipos não diferiram entre si (Figura 1C).

Os dados apresentados demonstraram que a menor biossíntese de SLs favorece o desenvolvimento vegetal, induzindo maior acúmulo de massa fresca e seca nas plantas (Figura 1). De fato, as SLs são conhecidas por modular a germinação de sementes de plantas parasitas, inibição da ramificação lateral e regulação do balanço hormonal nas plantas (BREWER et al. 2013). Além disso, as SLs estão 
intricadamente relacionadas com a regulação da arquitetura vegetal e o balanço de energia entre a parte aérea e o sistema radicular. Quanto à altura, a maior biossíntese de GA nas plantas de L19 induziu maior altura dessas plantas. As GAs promovem o maior alongamento celular e, consequentemente, do caule (WANG et al. 2017, RIZZA \& JONES 2018).

A baixa sensibilidade à auxina presente em plantas de dgt afetaram negativamente o desenvolvimento vegetal de plantas de tomateiro, especialmente da parte área. As auxinas são essenciais para o crescimento vegetal, regulando a dominância apical, ramificação lateral, expansão celular entre outros processos metabólicos (BRUMOS et al. 2018, FRICK \& STRADER 2018).

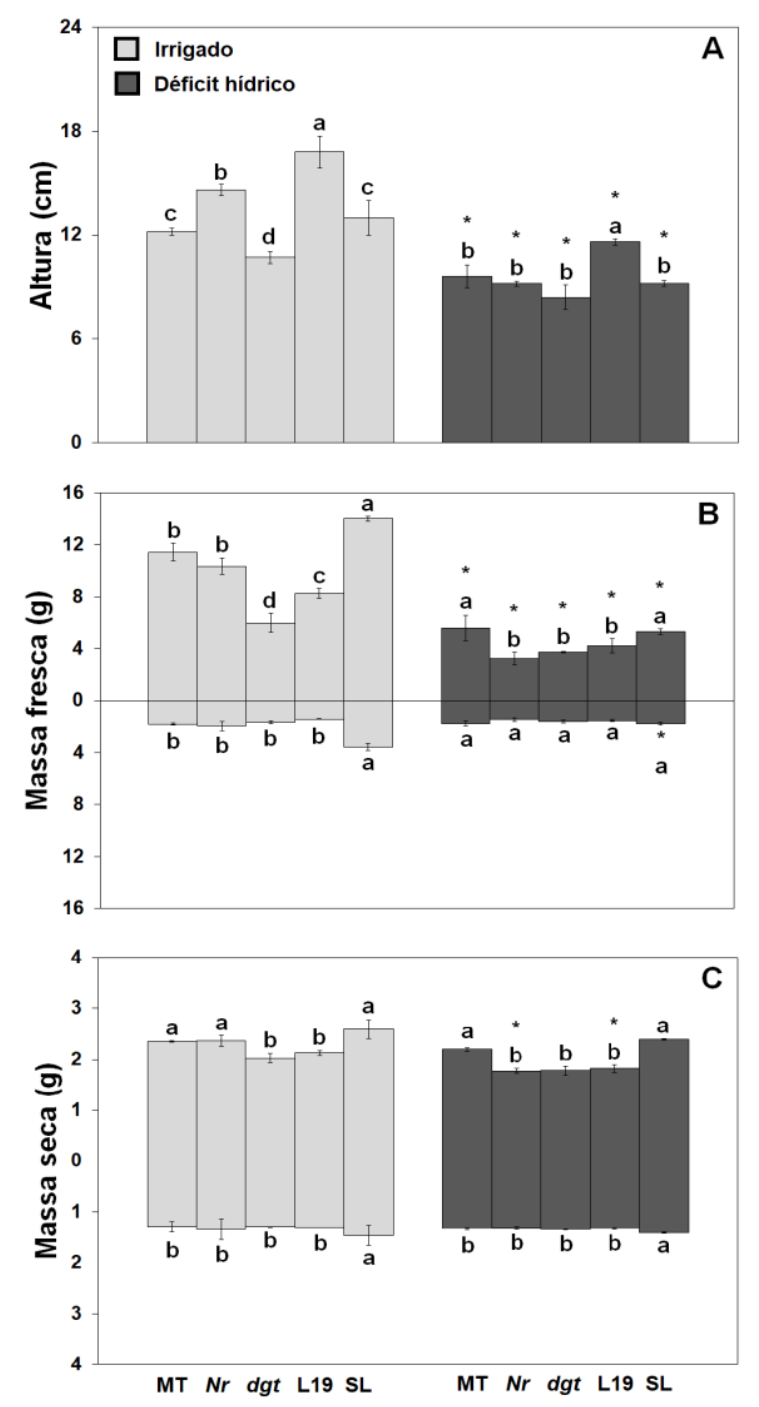

Figura 1. Parâmetros de genótipos de tomateiro cultivados em condições de estresse hídrico ou bem irrigado. (A) altura de plantas; (B) no eixo de coordenadas, valores acima e abaixo de 0 correspondem a massa fresca da parte aérea e das raízes, respectivamente; (C) no eixo de coordenadas, valores acima e abaixo de 0 correspondem a massa seca da parte aérea e das raízes, respectivamente. Os valores são as médias de cada tratamento $(n=3)$, e as barras são 0 erro padrão de cada tratamento. As letras na parte superior das barras representam as diferenças nas médias entre os genótipos na mesma condição de cultivo, e os asteriscos indicam as diferenças entre as condições para um mesmo genótipo. Ambos calculados usando o teste de Scott-Knot $(P \leq$ 0.05).

Figure 1. Parameters of tomato genotypes grown under drought or well irrigated conditions. $(A)$ height of the plant; $(B)$ on the coordinate axis, values above and below 0 corresponding to the fresh weight of the shoot and roots, respectively; $(C)$ on the coordinate axis, values above and below 0 corresponding to the dry weight of the shoot and roots, respectively. The values are as means of each treatment $(n=$ 3), and the bars are the standard error of each treatment. The letters at the top of the bars represent differences in means among genotypes within the same condition, and asterisks indicate differences between conditions within the same genotype. Both were calculated using the Scott-Knot test $(P \leq$ 0.05). 
Sob condição irrigada, observou-se maior conteúdo relativo de água (CRA) em plantas de $N r$, dgt e SL em comparação à MT e L19 (Figura 2A). Quanto ao extravasamento de eletrólitos, não verificou diferença estatística entre os genótipos (Figura 2B). A análise de extravasamento de eletrólitos indica o nível de estresse oxidativo das plantas, e na condição irrigada nota-se que todos os genótipos apresentavam o mesmo nível de estresse. Quanto ao CRA, aparentemente, a baixa sensibilidade ao etileno e à auxina e a baixa biossíntese de SLs induziram um maior teor de água no tecido vegetal das plantas de tomateiro.
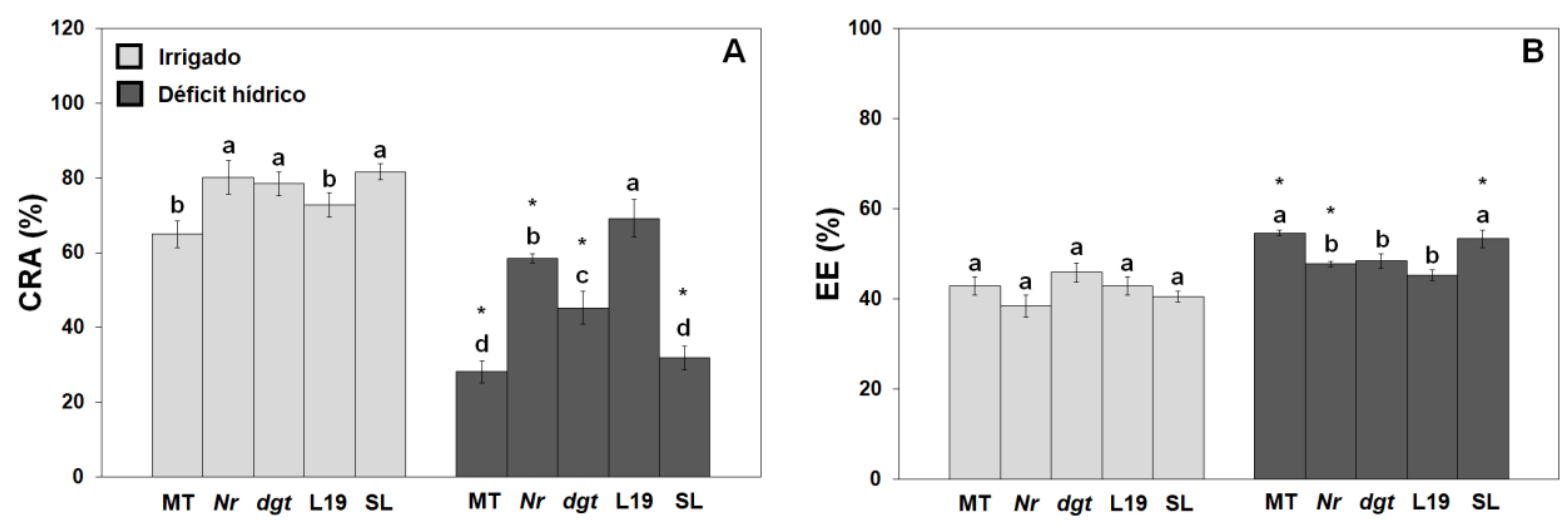

Figura 2. Parâmetros de genótipos de tomateiro cultivados em condições de estresse hídrico ou bem irrigado. (A) conteúdo relativo de água nas plantas (CRA); (B) extravasamento de eletrólitos (EE). Os valores são as médias de cada tratamento $(n=3)$, e as barras são o erro padrão de cada tratamento. As letras na parte superior das barras representam as diferenças nas médias entre os genótipos na mesma condição de cultivo, e os asteriscos indicam as diferenças entre as condições para um mesmo genótipo. Ambos calculados usando o teste de Scott-Knot $(P \leq 0.05)$.

Figure 2. Parameters of tomato genotypes grown under conditions of water stress or well irrigated. (A) relative water content in the plants (CRA); (B) leakage of electrolytes (EE). The values are as means of each treatment $(n=3)$, and the bars are the standard error of each treatment. The letters at the top of the bars represent differences in means among genotypes within the same condition, and asterisks indicate differences between conditions within the same genotype. Both were calculated using the Scott-Knot test $(P \leq 0.05)$.

\section{Controle hormonal do crescimento do tomateiro sob condição de déficit hídrico}

A altura de todos os genótipos foi inibida pelo déficit hídrico, contudo, plantas de L19 nesta condição apresentaram maior altura em comparação aos demais genótipos (Figura $1 \mathrm{~A}$ ). Similar à altura das plantas, a limitação da disponibilidade de água causou inibição da massa fresca da parte aérea de todos os genótipos (Figura 1B). Apesar da redução da massa fresca sob déficit hídrico, plantas de MT e SL exibiram maior massa fresca da parte aérea quando comparado aos genótipos dgt, $\mathrm{Nr}$ e L19. A massa fresca do sistema radicular foi negativamente afetada pelo déficit hídrico apenas em plantas de SL, embora não tenha diferido dos outros genótipos (Figura 1B).

Quanto a massa seca da parte aérea, verificou-se que as plantas de $\mathrm{Nr}$ e L19 foram negativamente afetadas pelo déficit hídrico (Figura 1C). Além disso, plantas de MT e SL proporcionaram os maiores valores de massa seca da parte aérea sob condição de déficit hídrico quando comparado aos demais genótipos (Figura 1C). Por outro lado, a massa seca do sistema radicular não foi influenciada pelo déficit hídrico, sendo que plantas de SL apresentaram maior massa seca do sistema radicular (Figura 1C).

De fato, a redução da disponibilidade hídrica induz uma série de processos nas plantas que levam ao fechamento estomático, reduzindo assim a assimilação de carbono e o crescimento vegetal (MARTINSTPAUL et al. 2017, AGURLA et al. 2018). Neste trabalho, podemos observar que todos os genótipos foram afetados negativamente pelo déficit hídrico. Mas as plantas com baixa sensibilidade ao etileno ( $\mathrm{Nr}$ ), baixa sensibilidade à auxina (dgt) e elevada biossíntese de GA (L19) foram mais suscetíveis ao déficit hídrico, exibindo redução da massa fresca e seca da parte aérea. Por outro lado, embora plantas de MT e SL (baixa biossíntese de estrigolactonas) tenham apresentado redução da massa fresca da parte aérea, estas mantiveram níveis similares de massa seca quando comparado à condição irrigada.

A massa fresca está associada especialmente ao teor de água da folha. Dentre os processos afetados pelo déficit hídrico, a expansão celular e, consequentemente, a expansão foliar é a mais sensível (ANJUM et al. 2017, NELISSEN et al. 2018, KOCH et al. 2019). Por outro lado, a fotossíntese tem se mostrado como um processo mais tolerante ao déficit hídrico (SEHGAL et al. 2017). Isso explicaria porque, 
embora tenha havido redução da massa fresca em todos os genótipos, a massa seca foi inibida apenas em plantas de $\mathrm{Nr}$ e L19 (Figura 1).

Todos os genótipos, exceto L19 que manteve maior nível de CRA, exibiram redução CRA sob condição de déficit hídrico (Figura 2A). Além disso, plantas de MT e SL induziram os menores níveis de CRA sob déficit hídrico. Quanto ao extravasamento de eletrólitos, observa-se que o déficit hídrico induziu aumento do estresse oxidativo em plantas de MT, $\mathrm{Nr}$ e SL; embora $\mathrm{Nr}$, juntamente com L19 e dgt, tenha apresentados os menores níveis de extravasamento de eletrólito (Figura 2B).

Plantas de SL e MT apresentaram os menores valores de CRA e maiores níveis de extravasamento de eletrólitos quando submetidas ao déficit hídrico (Figura 2A). Contudo, estes genótipos foram os únicos a não sofrerem redução do acúmulo de massa seca da parte área em função da restrição hídrica. Estes resultados indicam uma maior capacidade de manutenção do acúmulo de carbono apesar do baixo conteúdo de água foliar e aumento do estresse oxidativo. Por outro lado, embora plantas de L19, com elevada biossíntese de GA, tenham mantido níveis semelhantes de CRA em ambas as condições, elas apresentaram redução da altura, massa fresca e seca da parte aérea (Figura 1).

\section{CONCLUSÃO}

Com base nos dados obtidos, nós concluímos que a redução da sensibilidade ao etileno e à auxina em plantas de $\mathrm{Nr}$ e dgt, respectivamente, e maior biossíntese de GA em plantas de L19 tornam as plantas mais sensíveis às limitações hídricas em comparação ao seu tipo selvagem MT. Por outro lado, a menor biossíntese de estrigolactonas parece não ter afetado a resposta de plantas de tomateiro ao déficit hídrico.

\section{REFERÊNCIAS}

AGURLA S et al. 2018. Mechanism of stomatal closure in plants exposed to drought and cold stress. Advances in Experimental Medicine and Biology 1:215-231.

ALGHABARI $\mathrm{F}$ et al. 2014. Effect of Rht alleles on the tolerance of wheat grain set to high temperature and drought stress during booting and anthesis. Journal of Agronomy Crop Science 200: 36-45.

ANJUM AS et al. 2017. Growth and developmental responses of crop plants under drought stress: a review. Zemdirbyste - Agriculture 104: 267-276.

BASSEL GW et al. 2008. procera is a putative DELLA mutant in tomato (Solanum lycopersicum): effects on the seed and vegetative plant. Journal of Experimental Botany 59: 585-593.

BREWER PB et al. 2013. Diverse roles of strigolactones in plant development. Molecular Plant 6: 18-28.

BRUMOS $\mathrm{J}$ et al. 2018. Local auxin biosynthesis is a key regulator of plant development. Developmental Cell 47: $306-$ 318.

CARRERA E et al. 2012. Characterization of the procera tomato mutant shows novel functions of the SIDELLA protein in the control of flower morphology, cell division and expansion, and the auxin-signaling pathway during fruit-set and development. Plant Physiology 160: 1581-1596.

CARVALHO RF et al. 2011. Convergence of developmental mutants into a single tomato model system: 'Micro-Tom' as an effective toolkit for plant development research. Plant Methods 7: 18.

COELHO FILHO MA et al. 2013. The involvement of gibberellin signaling in the effect of soil resistance to root penetration on leaf elongation and tiller number in wheat. Plant Soil 371: 81-94.

CUI M et al. 2015. Ethylene increases accumulation of compatible solutes and decreases oxidative stress to improve plant tolerance to water stress in Arabidopsis. Journal of Plant Biology 58: 193-201.

DE OLLAS C \& DODD IC. 2016. Physiological impacts of ABA-JA interactions under water-limitation. Plant Molecular Biology 91: 641-650.

FAHAD $S$ et al. 2017. Crop production under drought and heat stress: plant responses and management options. Frontiers in Plant Science 8: 1-16.

FEITOSA SS et al. 2016. Fisiologia do Sesamum indicum L. sob estresse hídrico e aplicação de ácido salicílico. Irriga 21: 711-723.

FRICK EM \& STRADER LC. 2018. Roles for IBA-derived auxin in plant development. Journal of Experimental Botany 69 : 169-177.

GAION LA et al. 2018. Constitutive gibberellin response in grafted tomato modulates root-to-shoot signaling under drought stress. Journal of Plant Physiology 221: 11-21.

GERTMAN E \& FUCHS Y. 1972. Effects of abscisic acid and its interaction with other plant hormones on ethylene production in two plant systems. Planta 50: 194-195.

GARCÍA-HURTADO $\mathrm{N}$ et al. 2012. The characterization of transgenic tomato overexpressing gibberellin 20-oxidase reveals induction of parthenocarpic fruit growth, higher yield, and alteration of the gibberellin biosynthetic pathway. Journal of Experimental Botany 63: 5803-5813.

GRAVES WR \& GLADON RJ. 1985. Water stress, endogenous ethylene, and Ficus benjamina leaf abscission. HortScience 20: 273-275. 
HAMILTON AJ et al. 1990. Antisense gene that inhibits synthesis of the hormone ethylene in transgenic plants. Nature 346: 284-287.

HARTMAN K \& TRINGE SG. 2019. Interactions between plants and soil shaping the root microbiome under abiotic stress. Biochemical Journal 476: 2705-2724.

HASAN MM et al. 2021. ABA-induced stomatal movements in vascular plants during dehydration and rehydration. Environmental and Experimental Botany 186: 104436.

HASANUZZAMAN M et al. 2020. Reactive oxygen species and antioxidant defensive in plants under abiotic stress: revisiting the crucial role of a universal defense regulator. Antioxidants 9: 1-52.

HUNTER MC et al. 2021. Cover crop effects on maize drought stress and yield. Agriculture, Ecosystems and Environment 311: 1-10.

KAGE $\mathrm{H}$ et al. 2004. Root growth and dry matter partitioning of cauliflower under drought stress conditions: measurement and simulation. European Journal of Agronomy 20: 379-394.

KAPOOR D et al. 2020. The impact of drought in plant metabolism: how to exploit tolerance mechanisms to increase crop production. Applied Sciences 10: 1-19.

KELLY MO \& BRADFORD KJ. 1986. Insensitivity of the diageotropica tomato mutant to auxin. Plant Physiology 82: 713717.

$\mathrm{KOCH}$ G et al. 2019. Leaf production and expansion: A generalized response to drought stresses from cells to whole leaf biomass - A case study in the tomato compound leaf. Plants 8: 409.

KOVALESKI AP \& GROSSMAN JJ. 2021. Standardization of electrolyte leakage data and a novel liquid nitrogen control improve measurements of cold hardiness in woody tissue. Plant Methods 17: 1-20.

LANDJEVA $S$ et al. 2008. The contribution of the gibberellin-insensitive semi-dwarfing $(R h t)$ genes to genetic variation in wheat seedling growth in response to osmotic stress. Journal of Agricultural Science 146: 275-286.

LIANG G et al. 2020. Effects of drought stress on photosynthetic and physiological parameters of tomato. Journal of the American Society for Horticultural Science 145: 12-17.

LIU T et al. 2013. Identification of drought stress-responsive transcription factors in ramie (Boehmeria nivea L. Gaud). BMC Plant Biology 13: 130.

LIU $X$ et al. 2016. The NF-YC-RGL2 module integrates GA and ABA signalling to regulate seed germination in Arabidopsis. Nature Communication 7: 12768.

MARTIN-STPAUL N et al. 2017. Plant resistance to drought depends on timely stomatal closure. Ecology Letters 1: 1-11.

MODANESI S et al. 2020. Do satellite surface soil moisture observations better retain information about crop-yield variability in drought conditions? American Geophysical Union 1: 1-32.

NELISSEN H et al. 2018. The reduction in maize leaf growth under mild drought affects the transition between cell division and cell expansion and cannot be restored by elevated gibberellic acid levels. Plant Biotechnology Journal 16: 615-627.

PARRY MAJ et al. 2005. Prospects for crop production under drought: research priorities and future directions. Annals of Applied Biology 147: 211-226.

PIMENTA LANGE MJ \& LANGE T. 2006. Gibberellin biosynthesis and the regulation of plant development. Plant Biology 8: 281-290.

RIZZA A \& JONES AM. 2018. The makings of a gradient: spatiotemporal distribution of gibberellins in plant development. Current Opinion in Plant Biology 47: 9-15.

RUIZ-LOZANO JM et al. 2016. Arbuscular mycorrhizal symbiosis induces strigolactone biosynthesis under drought and improves drought tolerance in lettuce and tomato. Plant, Cell and Environment 39: 441-452.

SARWAT M \& TUTEJA N. 2017. Hormonal signaling to control stomatal movement during drought stress. Plant Gene 1: 1-51.

SEHGAL A et al. 2017. Effects of drought, heat and their interaction on the growth, yield and photosynthetic function of lentil (Lens culinaris Medikus) genotypes varying in heat and drought sensitivity. Frontiers in Plant Science 8: 1-22.

SELLIN A et al. 2014. Rapid and long-term effects of water deficit on gas exchange and hydraulic conductance of silver birch trees grown under varying atmospheric humidity. Plant Biology 14: 72-84.

SERGIEV I et al. 2019. Exogenous auxin type compounds amend PEG-induced physiological responses of pea plants. Scientia Horticulturae 248: 200-205.

SHI H et al. 2014. Modulation of auxin content in Arabidopsis confers improved drought stress resistance. Plant Physiology and Biochemistry 82: 209-217.

TURNER NC. 1981. Techniques and experimental approaches for the measurement of plant water status. Plant Soil 58: 339-366.

VISENTIN I et al. 2016. Low levels of strigolactones in roots as a component of the systemic signal of drought stress in tomato. New Phytologist 212: 954-963.

WANG C et al. 2008. Influence of water stress on endogenous hormone contents and cell damage of maize seedlings. Journal of Integrative Plant Biology 50: 427-434.

WANG Y et al. 2017. Gibberellin in plant height control: old player, new story. Plant Cell Report 36: 391-398.

ZHU T et al. 2018. Mitochondrial alternative oxidase-dependent autophagy involved in ethylene-mediated drought tolerance in Solanum lycopersicum. Plant Biotechnology Journal 16: 2063-2076. 